\title{
Spontaneous regression of an untreated neuroblastoma
}

\author{
L. GARVALHO \\ St. Paul's Eye Hospital, Liverpool
}

Neuroblastomas are highly malignant neoplasms arising from neuroblasts in one of the following sites: adrenal medulla, sympathetic ganglia, or in any ectopic adrenal tissue. They account for 12 to 15 per cent. of tumours in children and approximately half the $\overrightarrow{\vec{F}}$

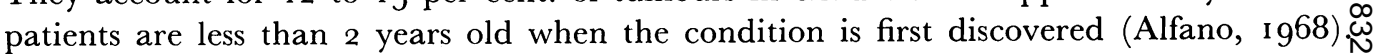
However, neuroblastomas are one of the few malignant tumours which are known to under $\frac{\text { ? }}{3}$ go remission.

Virchow (1864), who was the first to recognize the neural origin of neuroblastoma, referred to it as glioma. Pepper ( I gor) reported six cases of metastases to the liver (Pepper type), Hutchison (1907) reported metastases to the skull and orbit (Hutchison type) and Wright (1910) suggested the term neuroblastoma when he showed the similarity of the rosettes and fibril bundles to those in the embryonal, adrenal, and sympathetic ganglia은

Ellsworth (see Alfano, 1968) stated that it was extremely difficult to evaluate cases de cribed with remission or spontaneous cure (which may be as high as I 5 per cent.) because most cases had been treated. Vogel, Coddon, Simon, and Gitlow (1970) stated that the best results in terms of regression and obliteration of metastatic neuroblastoma tissue occu㽞 in patients who are less than 2 years old, with metastases restricted to the abdomen or chest $\stackrel{0}{\rightleftarrows}$ Conversely, patients with bony metastases over the age of 2 years do not respond well toğ therapy and the condition usually runs a short and fatal course. Schneider, Becker, and Krasna (1965), in a review of 56 cases in the neonatal period, found that 52 per cent. had. soft tissue metastases and 3.2 per cent. had bony growths. Sutow, Gehan, Heyer, Kung, Miller, Murphy, and Traggis (1970) found that 60 per cent. of patients over the age of 2 years had osseous metastases. King, Storaasli, and Bolande (196I), in a study of $25^{3}$. patients, reported that fourteen with either no metastases or non-bony metastases, were alive I to I 7 years after diagnosis. By comparison, eleven patients with bony metastases survived only 4 days to 6 months after diagnosis.

This case is reported because of hitherto unreported features.

\section{Case report}

A baby boy, born at full-term after a normal gestation on September 9, 1949, was admitted to hos pital at the age of 4 months with a swelling on the outer side of the right eye.

\section{Examination}

The cardiovascular and respiratory systems showed no abnormality. A large abdominal mass extended from the left costal region to the umbilicus, and numerous small lumps were palpable in the skin. 
There was a smooth, fluctuant swelling at the right upper lid, right parietal region, and on the right ramus of the mandible, and small swellings on several ribs as well as in the sub-cutaneous tissue of the chest and left axilla. A biopsy of a left axillary gland on January 28, 1950, established the diagnosis of neuroblastoma (Dr. W. K. McGinley).

Because of the extent of the metastases, the child's poor general condition, his remote chances of survival, and the mother's reluctance for treatment to be undertaken, he was taken home.

Much to the surprise of the Paediatric Unit, the mother returned with the child a year later. Most of the secondaries had disappeared and the primary swelling was considerably smaller, only one-third of its original size. It was then thought that this was one of the rare spontaneous cures, but a radiograph of the skull showed deposits of secondary tumours in the frontal, parietal, and sphenoidal bones. The abdominal mass was occupying the entire left upper quadrant. There was no readily available piece of tumour tissue for another biopsy. A full blood analysis was reported as normal. A radiograph dated February, I95 I, was described as follows:

Skull: Soft tissue swelling over the region of right orbit with some destructive bone changes. There is also possibly some bone thinning in the lesser wing of the sphenoid and also in the greater wing behind the eyc. There is also an area of osteoporosis about the size of a half-penny in the mid-parietal region on the right side. The appearance is compatible with that of secondary metastases.

Abdomen: There appears to be a mass with calcification in the left renal area (Dr. G. Scarrow).

The patient was re-admitted to hospital on May 28, 1954, being now aged $3 \frac{1}{2}$ years because of pain in the right eye and a discharge from both eyes. The abdominal mass was still palpable. The eyes showed right and left mucopurulent conjunctivitis and right scleritis. This cleared with local treatment and the patient was sent home (Fig. I).

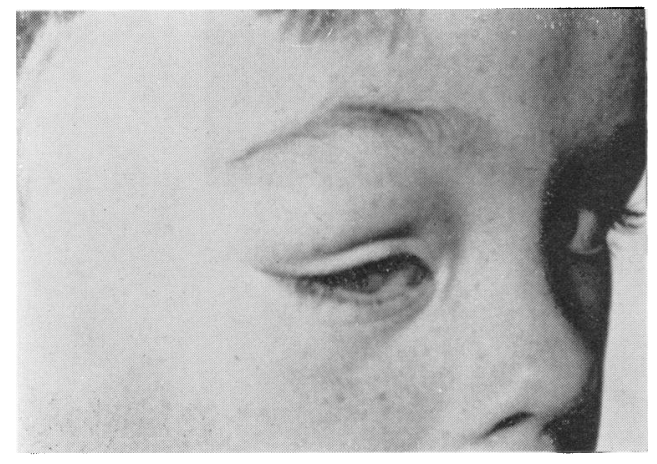

FIG. I The patient at 5 years of age, showing the swelling on the outer side of the right eye

3 years later the main complaint was swelling over the right eye and of the right upper eyelid and also that the eye was pushed forwards and downwards. The abdominal mass was still palpable. Eye examination at the time showed the presence of an enlarged right lacrimal gland and displacement of the eye downwards and inwards. There was also diffuse soft swelling of the upper eyelid. The neuroblastoma was thought to be active by one paediatrician but not by the other. No treatment was given because of the mother's continued reluctance for her child to be subjected to surgery.

\section{Progress}

In October, 1964, after a further Io years, there was a large tumour involving the right upper lid extending back into the orbit. The right eye was displaced downwards. There were also what appeared to be a soft swelling of the right temporal fossa and behind the right ear, and this was thought to be due to the presence of secondaries. Plastic surgery, though considered at the time, was not carried out because of the underlying displacement of the right eye and destruction of the bony orbit. 
Ocular examination in February, 1969, when the patient was aged 19 years, showed the visual acuity in the right eye with $-1.5 \mathrm{D}$ sph., $+3 \mathrm{D}$ cyl., axis $105^{\circ}$ to be $6 / 60$. The visual acuity in the left eye without correction was 6/6. There was swelling of the right temporal region, the right upper lid was oedematous and ptosed, and the fundi were normal. The pupils were equal and reactive to light, and the ocular movements showed limitation of elevation and abduction.

A skull radiograph taken in 1972 , when the patient was 22 years old, was reported as follows:

There is deformity of the superior margin of the right orbit. There is some linear sclerosis of the occipital region on the right side. Similar sclerosis giving a bizarre appearance is present in the parietal region on the right side. I believe this patient has had neuroblastoma.

The appearances are compatible with metastases in the skull vault and possibly in the right orbit" (Fig. 2).

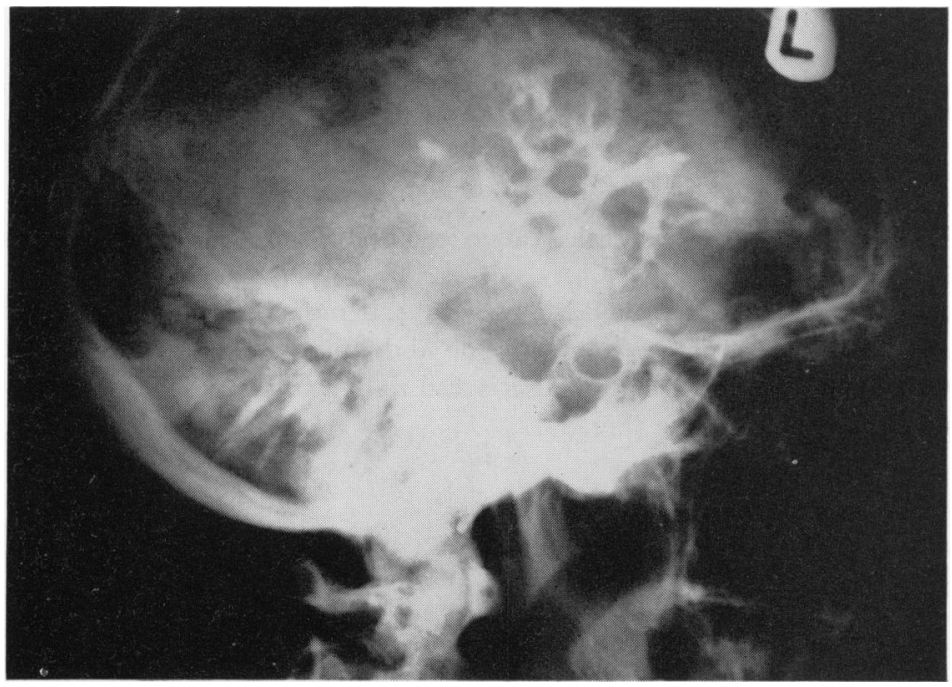

FIG. 2 Radiograph of skull in 1972. Patient aged 22 yrs

The patient's general appearance at this time is shown in Fig. 3.

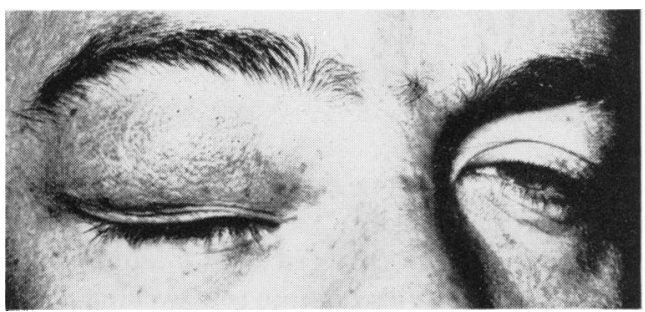

FIG. 3 The patient at 22 years of age

\section{Discussion}

The survival of patients with neuroblastoma (Vogel and others, 1970) is closely related to the natural history of the tumour. The age at onset of the disease, the site of origin of the lesion, the presence or absence of osseous metastases, and the spontaneous disappearance or maturation of the tumour are all of prognostic importance.

Helson (197 I), after studies in vitro, made the following suggestions: "Therapy in neuroblastomas might be directed towards reducing the blocking factor and tumour mass without suppressing the cell-mediated immune reaction". Bill (1968) stated that Everson and 
Cole had collected and described i 76 cases of all types of cancer and that the largest group, 29 (i.e. approximately $\mathrm{I} 7$ per cent.), comprised cases of neuroblastoma with regression. Therefore, neuroblastoma has the highest rate of regression of any human malignancy. Bill concluded, however, that the chances were small when the tumour originated in the adrenal gland.

Spontaneous maturation of a malignant neuroblastoma to the more benign ganglioneuroma is infrequent, but several cases have been reported. Wyatt and Farber (I 94 I) reported ten cures in a series of forty infants and children observed for a period of $\mathrm{I} 0$ years. Some cures have followed surgical removal of a tumour and others have occurred even after incomplete removal either through spontaneous maturation or through necrosis and haemorrhage. Complete recovery has been recorded after the use of deep x-ray therapy even after histologically proved metastases from a primary tumour of the adrenal to the liver. No cures have been observed after skeletal metastases with the one exception reported by Goldring (195I), whose patient had deep x-rays to the tumour and liver, after which somewhat indefinite skeletal secondaries in the head of the humerus and skull disappeared spontaneously.

The present case is interesting in that spontaneous cure appears to have taken place in the presence of bony metastases with no therapy whatsoever.

I should like to thank Dr. White Jones for allowing me to study and publish this case.

\section{References}

alfano, J. E. (1968) Trans. Amer. Acad. Ophthal. Otolaryng., 72, 830

BILl, A. H., JR (1968) 7. pediat. Surg., 3, 103

GOLdRING, D. (I95I) F. Pediat., 38, 23 I-234

HELSON, L. (I97I) Lancet, I, I075

hUtchison, R. (1907) Quart. F. Med., I, 33

king, R. L., StoraAsli, J. P., and bolande, R. P. (I96I) Amer. F. Roentgenol., 85, 733

PEPPER, W. (I9OI) Amer. J. med. Sci., I21, 287

SCHNeIDER, K. M., BECKer, J. M., and KRASNA, I. H. (1965) Pediatrics, 36, 359

sutow, w. W., GeHAN, E. A., HeYer, R. M., KUNG, F. H., Miller, R. W., MURPhy, M. L., and

TRAGGIS, D. G. (1970) Ibid., 45, 800

virchow, R. ( 1864) Virchow's Arch. Path. Anat., 30, 272

VOGEL, J. M., Coddon, D. R., Simon, N., and Gitlow, s. E. (1970) Canier (Philad.), 26, I 354

WRIGHT, J. H. (19IO) F. exp. Med., 12, 556

WYatt, G. M., and farber, s. (194I) Amer. F. Roentgenol., 46, 485 